\title{
MÉTODOS DE AMOSTRAGEM E GEOESTATÍSTICA PARA ESTIMATIVA DO NÚMERO DE FUSTES E VOLUME EM PLANTIOS DE Eucalyptus grandis
}

\author{
José Márcio de Mello $^{1}$, Frederico Silva Diniz ${ }^{2}$, Antônio Donizette de Oliveira ${ }^{1}$, \\ José Roberto Soares Scolforo ${ }^{1}$, Fausto Weimar Acerbi Júnior ${ }^{3}$, Cláudio Roberto Thiersch ${ }^{4}$ \\ ${ }^{1}$ Eng. Florestal, Dr., Depto. de Ciências Florestais, UFLA, Lavras, MG, Brasil - josemarcio@ufla.br - donizete@ufla.br - jscolforo@ufla.br \\ ${ }^{2}$ Eng. Florestal, M.Sc., CONPACEL, Americana, SP, Brasil - dfrederico@ conpacel.com.br \\ ${ }^{3}$ Eng. Florestal, M.Sc., Depto. de Ciências Florestais, UFLA, Lavras, MG, Brasil - fausto@ufla.br \\ ${ }^{4}$ Eng. Florestal, Dr., Votorantim Celulose e Papel S/A, Jacareí, SP, Brasil - claudio.thiersch@vcp.com.br \\ Recebido para publicação: 01/11/2007 - Aceito para publicação: 25/06/2008
}

\begin{abstract}
Resumo
Os objetivos deste trabalho foram estimar o número de fustes e o volume de madeira por unidade de manejo, por meio dos estimadores da amostragem casual simples (ACS) e do interpolador geoestatístico, para parcelas circulares e em linha, em três intensidades amostrais, e comparar as estimativas obtidas por esses métodos com o valor observado (censo) de cada unidade de manejo. A área de estudo abrange quatro talhões de Eucalyptus grandis, totalizando 104,71 ha, com idade variando de três a quatro anos, pertencentes à Ripasa S/A Celulose e Papel. Fez-se a contagem do número de fustes de cada talhão por meio de fotografias aéreas digitais. A avaliação da exatidão da estimativa do número de fustes e do volume foi efetuada por meio da matriz de exatidão. A predição espacial do número de fustes e do volume em cada talhão foi feita por meio da krigagem, com simulação em cada talhão. Houve diferença significativa entre os métodos avaliados para número de fustes, nas três intensidades amostrais. Nas maiores intensidades amostrais, os métodos que envolveram parcelas circulares foram mais exatos do que nas parcelas em linhas. Na intensidade amostral 1:10, as parcelas em linha foram mais exatas do que as circulares. Para a variável volume, o teste $F$ foi não-significativo para as duas maiores intensidades amostrais (1:4 e 1:7), e na menor intensidade houve diferença estatística entre os métodos. Por meio da matriz de exatidão, tanto para número de fustes quanto para volume, os métodos mais exatos foram os que se baseiam em parcelas circulares, e para a intensidade 1:10, os métodos que se baseiam em parcelas em linha foram mais exatos.

Palavras-chave: Inventário florestal; forma de parcelas.
\end{abstract}

\begin{abstract}
Sampling methods and geostatic for estimate of number of stems and volume of Eucalyptus grandis plantations. The objectives of this work were to estimate the number of stems and wood volume per unit of management, by Simple Random Sampling (ACS) and geostatistic interpolator, for circular and row plots in three sample intensities; in order to compare the estimates obtained by the application of different methods, with the observed value (census) of each unit of management. The study area included four stands of Eucalyptus grandis, totaling 104.71 ha at ages varying from three to four years, belonging to Ripasa S/A Cellulose and Paper Company. Stem number of each stand was counted using digital aerial pictures. The evaluation of the accuracy of the estimate of the stem number and volume were made by accuracy matrix. The space prediction of the stem number and of volume, in each stand, were done by krigage with simulation in each stand. There was significant difference among the appraised methods for stem number in the three sample intensities. In the highest sample intensities the methods that involved circular plots were more precise than the row plot. In the sample intensity 1:10, the row plots were more precise than the circular ones. For the variable volume, the $\mathrm{F}$ test was not significant for the two highest sample intensities $(1: 4$ and 1:7) and in the highest intensity there was statistical difference among the methods. Through the accuracy matrix for stem number as for volume, the most exact methods were those based on circular plots and for the intensity $1: 10$, the methods based on linear plots were more precise.

Keywords: Forest inventory; plots form.
\end{abstract}




\section{INTRODUÇÃO}

As informações referentes ao estoque de madeira, nos sentidos qualitativo e quantitativo, necessárias ao planejamento são obtidas por meio do inventário florestal. Essas informações, que normalmente se referem ao volume da floresta e/ou a outra variável dendrométrica, podem ser obtidas por procedimentos de amostragem ou pela enumeração total das árvores, procedimento conhecido como censo.

Entretanto, no caso das florestas plantadas, há uma grande variabilidade no espaçamento entre as plantas, ocasionada por equipes mal treinadas para o preparo do solo e por áreas onde não há plantio, seja devido às condições do próprio relevo ou pela mortalidade das mudas, causada por pragas, doenças e intempéries. Em muitos casos, não é possível detectar esses problemas e, consequentemente, essas áreas não são desconsideradas na área do talhão. Na maioria das vezes, a amostra não é representativa a ponto de detectar essas variações. A questão amostral se agrava ainda mais quando se pretende atingir erros menores para a unidade de manejo (talhão).

Segundo Mello et al. (2006), os métodos usados para inventariar populações florestais buscam o menor erro, para uma mesma quantidade de trabalho, fixando a precisão desejada para as informações a serem levantadas e que, posteriormente, serão usadas no planejamento da empresa. Assim, torna-se importante investigar, para o tipo florestal específico, os métodos e os processos de amostragem que permitam reduzir o custo do inventário, o qual é diretamente influenciado pelo tempo de medição e pelo caminhamento (Cesaro et al., 1994).

Uma alternativa capaz de efetuar a predição de variáveis dendrométricas com eficácia e que não gera mais custos em relação aos métodos tradicionais é a utilização do interpolador geoestatístico, principalmente pela sua capacidade de considerar a autocorrelação entre as parcelas, a fim de aumentar a eficiência da estimativa.

Segundo Scolforo; Mello (2006), um dos problemas de se amostrar uma fisionomia florestal é a definição adequada do tamanho da unidade amostral, assim como a sua suficiência amostral. Esses parâmetros devem ser obtidos de forma precisa, a fim de representar a variabilidade da população.

As variações da forma e do tamanho das unidades amostrais constituem as variáveis fundamentais para a avaliação de sua aplicação prática (PÉLLICO NETTO e BRENA, 1997). A definição desses parâmetros tem sido decidida muito mais pela praticidade e operacionalidade de sua localização e demarcação em campo do que por qualquer outra argumentação (MOSCOVICH et al., 1999).

Dessa forma, os objetivos deste trabalho foram estimar o número de fustes e o volume de madeira por unidade de manejo, por meio dos estimadores da amostragem casual simples (ACS) e do interpolador geoestatístico, para parcelas circulares e em linha, em três intensidades amostrais, e comparar as estimativas obtidas pelos métodos com o valor paramétrico (censo) de cada unidade de manejo.

\section{MATERIAL E MÉTODO}

\section{Localização e caracterização da área}

A área de estudo abrange quatro unidades de manejo (talhões) de Eucalyptus grandis, totalizando 104,71 ha, com idades variando de três a quatro anos, de primeira rotação.

A área pertence à empresa Ripasa S/A Celulose e Papel, e o plantio localiza-se no município de Avaré, SP. O clima local, segundo Köppen, é classificado como Cwa do tipo mesotérmico, com temperatura média anual de $20,3{ }^{\circ} \mathrm{C}$ e precipitação anual de $1.274 \mathrm{~mm}$, não apresentando déficit hídrico. $\mathrm{O}$ clima é considerado subtropical, com estação seca. Os solos predominantes na área são Latossolo de textura média e Neossolo Quartzarênico, sendo pobres em nutrientes, apresentando caráter álico.

\section{Obtenção dos dados}

Amostragem casual simples (ACS)

Um dos métodos utilizados para a estimativa das características número de fustes e volume foi a amostragem casual simples (COCHRAN, 1977; PÉLLICO NETO; BRENA, 1997; SCOLFORO; MELLO, 2006). Por meio dele, obtiveram-se o número de fustes e o volume de cada talhão, através de parcelas circulares e em linha. Para cada forma de parcela, calculou-se, também, o erro padrão da média e, consequentemente, o erro do inventário, para as duas características em estudo. 
Interpolador geoestatístico - krigagem de bloco

A predição espacial do número de fustes e do volume, em cada talhão, foi feita por meio de krigagem, com simulação em cada talhão (bloco), a qual foi realizada numericamente (SOARES, 2000). Com o modelo geoestatístico da área, realizaram-se 3.000 simulações em cada ponto não amostrado dentro do talhão. Ao final, foram obtidos 3.000 valores médios espaciais de número de fustes e volume, para cada talhão. A partir deles, geraram-se a média das médias espaciais e a variância entre as médias, o que possibilitou estabelecer o erro do inventário e, consequentemente, o intervalo de confiança para número de fustes e volume, de cada talhão. Esse método foi denominado, por Journel;Huijbregts (1978), como simulação de bloco condicionada aos pontos amostrados, tendo sido descrito e aplicado por Mello (2004) e Soares (2000). Segundo esses autores, quando se pretende obter o valor médio da variável regionalizada Z, numa subárea $R$, ele pode ser obtido pela média dos valores krigados pontuais que compõem a subárea $R$. Essas análises foram realizadas no programa R, pelo pacote geoR (RIBEIRO JÚNIOR; DIGGLE, 2001).

Censo

A contagem do número de fustes presentes em cada talhão foi feita a partir de fotografias aéreas digitais de cada área. Elas receberam um tratamento de cores, para facilitar a contagem das copas, como mostrado na figura 1. Com a imagem trabalhada, fez-se a contagem manual das copas, utilizando-se um software de processamento de imagem em que se identificou cada copa manualmente. No final, o sistema gerava uma tabela com o número de copas e, consequentemente, o número de fustes por talhão.

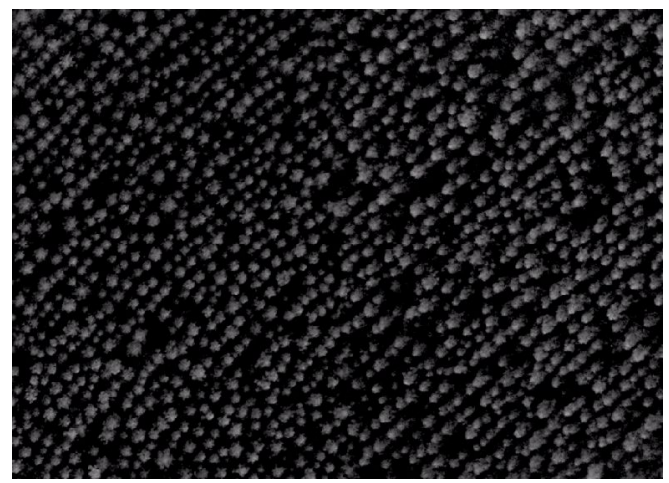

Figura 1. Fotografia aérea digital utilizada para a contagem do número de fustes.

Figure 1. Digital aerial picture used for counting of the stems.

Para calcular o volume observado de cada talhão, multiplicou-se o volume da árvore média, gerada a partir das parcelas circulares, pelo número de fustes obtido por meio do censo.

\section{Intensidade amostral}

Realizou-se um inventário pré-corte com uma fração amostrada de $0,255 \%$, correspondente a uma parcela a cada quatro hectares (1:4). As parcelas lançadas foram circulares e em linha, georreferenciadas e distribuídas de maneira a representar toda a área.

Algumas dessas parcelas foram selecionadas e distribuídas de forma sistemática na área, a fim de representarem parcelas para uma fração amostrada de $0,14 \%$, correspondente a uma parcela a cada sete hectares (1:7), e 0,1\% de área amostrada, correspondente a uma parcela a cada dez hectares (1:10). Ressalte-se que a intensidade de 1:10 representa o inventário florestal contínuo. O processamento das variáveis número de fustes e volume foi efetuado pelos estimadores da Amostragem Casual Simples.

\section{Forma das parcelas}

Parcelas circulares

A área das parcelas circulares foi de $500 \mathrm{~m}^{2}$. Nelas mediram-se a circunferência a $1,30 \mathrm{~m}$ de altura do solo (CAP) de todas as árvores, a altura das cinco árvores dominantes, a altura das árvores quebradas, o número de fustes e o número de falhas. Por meio da equação de afilamento utilizada pela 
empresa, obtiveram-se o volume por parcela e o volume da árvore média, para cada parcela. Ressalte-se que o volume médio por árvore foi utilizado para definir o volume das parcelas em linha.

Parcelas em linha

A justificativa para usar a parcela em linha, em plantios de eucalipto, é que as unidades no formato tradicional (circular ou retangular) não captam suficientemente bem o número de fustes por hectare. Isso pode ocorrer devido a diversos fatores, destacando erros de espaçamento e erros internos no mapeamento. No segundo caso, trata-se de situações que não são delimitadas no mapa, tal como estradas e carreadores abandonados, afloramento de rochas, manchas de florestas nativas e bacias de contenção de água, entre outros. A hipótese foi de que a parcela em linha consegue captar esses problemas ocorridos no mapeamento e no espaçamento de plantio. Segundo Robles (1978), as unidades amostrais estreitas e compridas são mais convenientes, do ponto de vista da desuniformidade do solo, e, com a forma comprida, é mais factível que as variações de fertilidade sejam alcançadas por igual nas diferentes unidades amostrais.

O ponto de referência para delimitar a parcela em linha foi o centro da diagonal entre duas árvores opostas de linhas adjacentes da parcela circular (Figura 2).
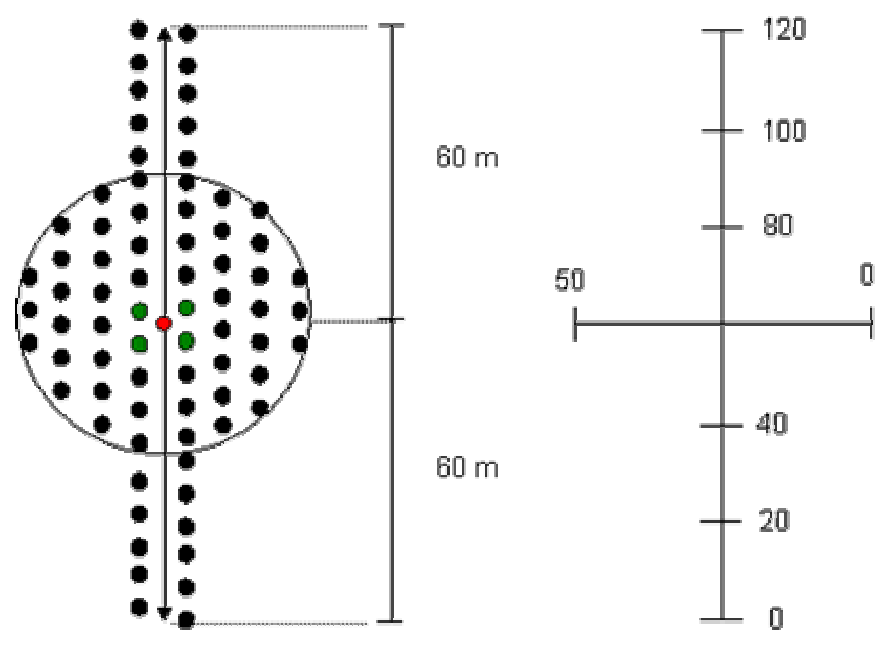

Figura 2. Esquema ilustrativo do lançamento de uma parcela em linha.

Figure 2. Illustrative outline of the release of a row plot.

A partir do ponto central da parcela circular, definiu-se a parcela em linha de 120 metros de comprimento, obedecendo-se ao alinhamento de plantio, em que se contou o número de covas e de fustes, dentre outras características de sanidade das árvores presentes nas duas linhas centrais. Do ponto central, caminharam-se 60 metros para uma direção e 60 metros para a direção oposta. A partir do ponto central, traçou-se uma linha de 50 metros, perpendicular à linha de plantio. Assim, determinou-se o espaçamento médio de plantio em cada parcela. As intensidades amostrais das parcelas em linha foram idênticas às das parcelas circulares, ou seja, de 1:4, 1:7 e 1:10 (1 parcela a cada 10 hectares).

Utilizou-se a parcela em linha para a obtenção do espaçamento médio de plantio. Para isso, contou-se o número de covas (árvores vivas e falhas) nas duas linhas centrais, ao longo dos 120 metros. A razão entre o comprimento $(120 \mathrm{~m})$ e o número de covas forneceu o espaçamento médio na linha. $\mathrm{Na}$ linha de 50 metros, perpendicular ao maior sentido, contou-se o número de linhas de plantio. Mediu-se, também, a distância/espaçamento entre as duas linhas centrais, a cada 20 metros. A razão do comprimento da linha $(50 \mathrm{~m})$ pelo número de linha, juntamente com a distância entre as linhas centrais, a cada 20 metros, possibilitou gerar o espaçamento médio entre linhas de plantio. Cada parcela em linha, dentro do talhão, gerou um valor de espaçamento médio. Essas informações permitiram definir o 
espaçamento médio de plantio e, consequentemente, o número de covas para o talhão. Por meio do índice de sobrevivência do plantio, obteve-se o número de fustes para o talhão.

Por meio do volume médio por árvore gerado pelo inventário florestal contínuo, juntamente com o número de fustes gerado a partir do espaçamento médio das parcelas em linhas, obteve-se o volume do talhão.

\section{Análise dos dados}

Caracterização do delineamento experimental

$\mathrm{O}$ delineamento utilizado foi em blocos casualizados. Cada talhão foi considerado o bloco e, portanto, recebeu os tratamentos avaliados descritos na tabela 1. Nesse tipo de delineamento, avaliaramse o número de fustes e o volume por talhão. O teste de média utilizado para comparar os tratamentos foi o desenvolvido por Scott e Knott (1974).

Esse delineamento foi aplicado para cada uma das três intensidades amostrais. A tabela 2 mostra a estrutura de análise de variância, para número de fustes e volume dos talhões.

Tabela 1. Descrição dos tratamentos avaliados no presente estudo.

Table 1. Description of the evaluated treatments in the present study.

\begin{tabular}{ll}
\hline Tratamento & \multicolumn{1}{c}{ Descrição } \\
\hline 1 & Aleatorização de parcelas circulares conforme cada intensidade amostral. \\
2 & $\begin{array}{l}\text { Aleatorização de parcelas em linhas conforme cada intensidade amostral. } \\
\text { Krigagem de bloco para volume e número de plantas (modelo espacial com informações de } \\
\text { parcelas circulares). }\end{array}$ \\
& $\begin{array}{l}\text { Krigagem de bloco para volume e número de plantas (modelo espacial com informações de } \\
\text { parcelas em linhas). } \\
\text { Censo - contagem de todos os fustes dentro de cada talhão. O volume do talhão foi gerado a partir } \\
\text { da informação da árvore média do inventário florestal contínuo. }\end{array}$ \\
\hline
\end{tabular}

Tabela 2. Análise de variância para número de fustes e volume.

Table 2. Variance analysis for shafts number and volume.

\begin{tabular}{lc}
\hline FV & GL \\
\hline Tratamentos & 4 \\
Bloco (talhão) & 3 \\
Erro & 12 \\
\hline Total & 19 \\
\hline
\end{tabular}

FV: Fator de variação; GL: Graus de liberdade.

Avaliação da exatidão das estimativas

Os testes estatísticos utilizados referem-se à média das características. Eles assumem a pressuposição de normalidade das características avaliadas. No caso de amostragem, não é suficiente acertar apenas o valor médio, é preciso avaliar a precisão (erro) ou a exatidão, quando se tem o valor paramétrico, das estimativas. Segundo Gomes (1990), a precisão ou a exatidão não tem distribuição normal. Assim, compará-lo por um teste de F significa negligenciar a condição de normalidade exigida por ele.

No presente trabalho, avaliou-se a exatidão, uma vez que se conhece o valor paramétrico das características (volume e número de fustes). Para comparar a exatidão dos procedimentos, utilizou-se a matriz de exatidão. Essa avaliação foi feita para cada método, com as diferentes intensidades amostrais (1:4, 1:7 e 1:10) e formas de parcelas. Para tal, geraram-se os erros dos quatro procedimentos (tratamentos) utilizados, em relação aos valores observados para número de fustes e volume de toda a área. A exatidão foi obtida pela relação entre as estimativas de cada método, das duas características em estudo, e o valor observado. Os métodos foram os seguintes: processamento do inventário com amostragem casual simples (ACS), para parcelas circulares e em linha, e krigagem de bloco, a partir dos modelos espaciais, ajustados para cada intensidade amostral e às duas formas de parcela. 


\section{RESULTADOS E DISCUSSÃO}

Nas figuras 3 e 4 são mostrados os valores totais de número de fustes e volume, nas três intensidades amostrais, considerando os quatro procedimentos de estimativas. A linha tracejada indica os valores reais das duas características, obtidas por meio do censo. Pode-se observar, claramente, que houve superestimativa do número de fustes e volume em relação ao censo dos quatro procedimentos avaliados nas três intensidades amostrais.

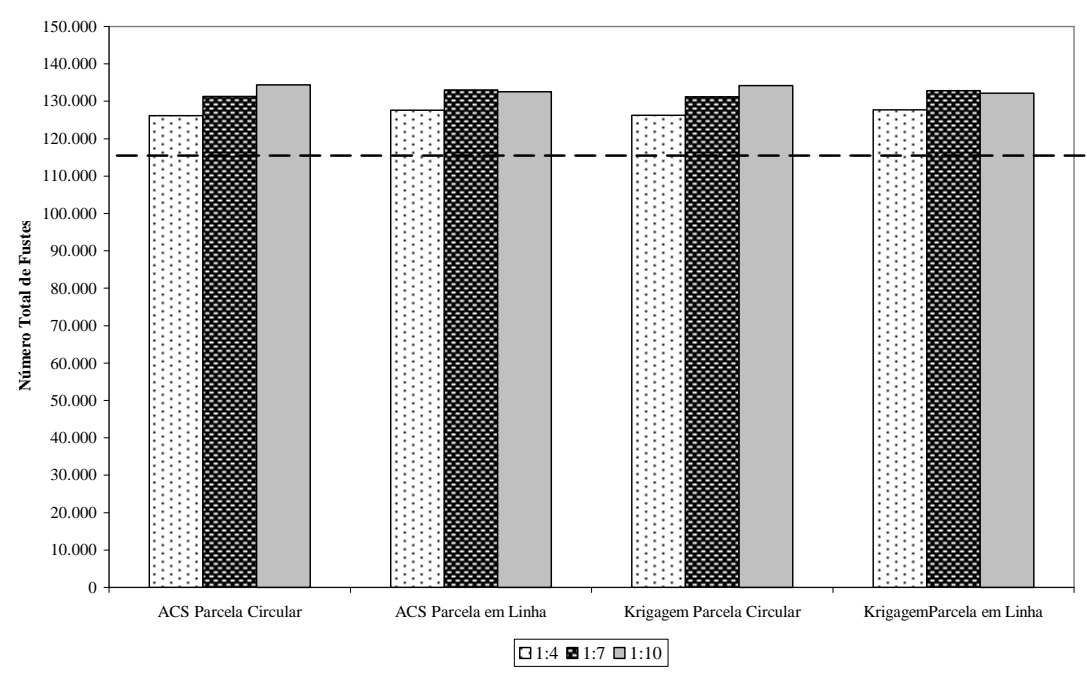

Figura 3. Número total de fustes estimados para cada tratamento, em três intensidades amostrais. A linha tracejada indica o valor observado.

Figure 3. Total stem number estimated for each treatment, in three samples intensities. The stippled line indicates the observed value.

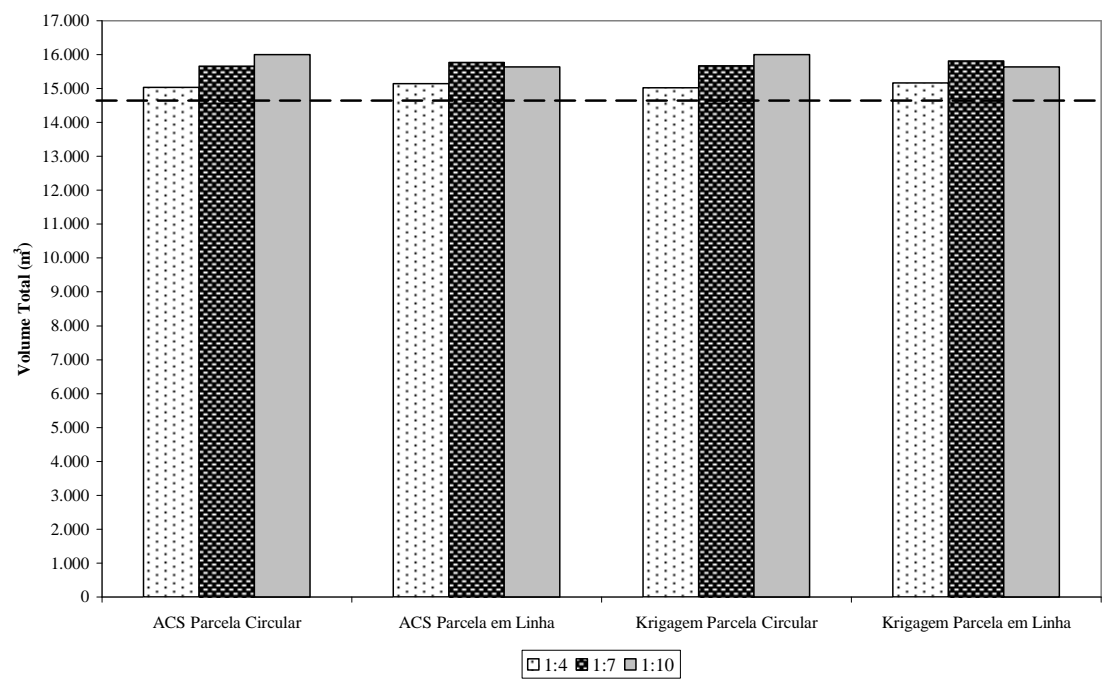

Figura 4. Volume total $\left(\mathrm{m}^{3}\right)$ estimado para cada tratamento, em três intensidades amostrais. A linha tracejada indica o valor observado.

Figure 4. Total volume $\left(\mathrm{m}^{3}\right)$ estimated per treatment, in three sampling intensities. The stippled line indicates the observed value. 
Nas tabelas 3, 4 e 5 estão as informações pertinentes aos resultados da análise de variância, em relação a número de fustes e volume, para as respectivas intensidades amostrais avaliadas.

Tabela 3. Análise de variância para número de fustes e volume, na intensidade 1:4.

Table 3. Variance analysis for stems number and volume, in the intensity 1:4.

\begin{tabular}{lccccccc}
\hline \multirow{2}{*}{ FV } & \multirow{2}{*}{ GL } & \multicolumn{3}{c}{ Número de fustes } & \multicolumn{3}{c}{ Volume } \\
\cline { 3 - 7 } & & QM & Fc & Pr>Fc & QM & Fc & Pr>Fc \\
\hline Tratamento & 4 & $4.397,13$ & 4,631 & 0,0171 & 51,70 & 1,765 & $0,2008^{\mathrm{NS}}$ \\
Talhão & 3 & $10.527,67$ & 11,088 & 0,0009 & $2.517,38$ & 85,918 & 0,0000 \\
Erro & 12 & 949,46 & & & 29,30 & & \\
Total corrig. & 19 & & & & & & \\
CV $(\%)$ & 2,57 & & & & 3,79 & & \\
\hline
\end{tabular}

FV: Fator de variação; G: Graus de liberdade; QM: Quadrado médio.

Tabela 4. Análise de variância para número de fustes e volume, na intensidade 1:7.

Table 4. Variance analysis for stems number and volume, in the intensity 1:7.

\begin{tabular}{lccccccc}
\hline \multirow{2}{*}{ FV } & \multirow{2}{*}{ GL } & \multicolumn{3}{c}{ Número de fustes } & \multicolumn{3}{c}{ Volume } \\
\cline { 3 - 7 } & & $\mathbf{Q M}$ & $\mathbf{F c}$ & $\mathbf{P r}>\mathbf{F c}$ & $\mathbf{Q M}$ & $\mathbf{F c}$ & Pr>Fc \\
\hline Tratamento & 4 & $12.107,58$ & 10,326 & 0,0007 & 162,63 & 1,473 & $0,2710^{\mathrm{NS}}$ \\
Talhão & 3 & $16.003,80$ & 13,649 & 0,0003 & $1.926,85$ & 17,481 & 0,0001 \\
Erro & 12 & $1.172,51$ & & & 110,23 & & \\
Total corrig. & 19 & & & & & & \\
CV $(\%)$ & 2,77 & & & & 7,1 & & \\
\hline
\end{tabular}

FV: Fator de variação; GL: Graus de liberdade; QM: Quadrado médio.

Tabela 5. Análise de variância para número de fustes e volume, na intensidade 1:10.

Table 5. Variance analysis for stems number and volume, in the intensity 1:10.

\begin{tabular}{lccccccc}
\hline \multirow{2}{*}{ FV } & \multirow{2}{*}{ GL } & \multicolumn{3}{c}{ Número de fustes } & \multicolumn{3}{c}{ Volume } \\
\cline { 3 - 7 } & & QM & Fc & Pr> Fc & QM & Fc & Pr>Fc \\
\hline Tratamento & 4 & $14.617,43$ & 9,512 & 0,0011 & 197,08 & 17,174 & 0,0001 \\
Talhão & 3 & $19.085,47$ & 12,419 & 0,0005 & $3.152,27$ & 274,707 & 0,0000 \\
Erro & 12 & $1.536,76$ & & & 11,48 & & \\
Total corrig. & 19 & & & & & & \\
CV $(\%)$ & 3,15 & & & & 2,28 & & \\
\hline
\end{tabular}

FV: Fator de variação; GL: Graus de liberdade; QM: Quadrado médio.

Em relação à variável número de fustes, a análise de variância mostrou que houve diferença significativa entre os tratamentos, nas três intensidades amostrais. $O$ maior coeficiente de variação foi de $3,15 \%$, referente à intensidade amostral 1:10. Segundo Gomes (1990), essa medida de variabilidade exerce forte impacto no quadrado médio do erro e, consequentemente, no valor de $\mathrm{F}$ (significância do teste).

$\mathrm{O}$ teste de médias mostrou que, para as três intensidades amostrais, o número de fustes determinado pelo censo foi diferente, estatisticamente, dos demais tratamentos (Tabelas 6, 7 e 8). Os tratamentos avaliados superestimaram sistematicamente o número de fustes em relação aos valores obtidos por meio do censo. Para número de fustes, pode-se utilizar qualquer um dos procedimentos estimativos, para qualquer uma das três intensidades amostrais. Assim, a estimativa pela parcela circular na intensidade de 1:10, que seria o inventário florestal contínuo, estimou com precisão o número de fustes.

A análise de variância realizada para volume indicou não haver diferença significativa entre os tratamentos, para as intensidades amostrais 1:4 e 1:7. Os coeficientes de variação foram de 7,1\%, 3,8\% e 2,3\% para as intensidades amostrais de 1:7, 1:4 e 1:10, respectivamente.

Nas maiores intensidades amostrais, 1:4 e 1:7, os tratamentos com parcelas circulares foram mais exatos do que os com parcelas em linha. Por outro lado, na intensidade amostral menor (1:10), os tratamentos com parcelas em linha foram mais exatos que os com parcelas circulares, uma vez que os valores estimados com a amostragem casual simples e krigagem com parcelas em linha apresentaram resultados mais próximos do valor paramétrico. 
Tabela 6. Teste de média Scott-Knott para número de fustes e volume, na intensidade 1:4.

Table 6. Means test Scott-Knott for stems number and volume, in the intensity 1:4.

\begin{tabular}{lccccc}
\hline \multicolumn{3}{c}{ Número de fustes } & \multicolumn{3}{c}{ Volume } \\
\hline Tratamentos* & Médias & Resultado & Tratamentos* & Médias & Resultado \\
\hline 5 & $1.139,50$ & $\mathrm{a} 1$ & 5 & 136,50 & $\mathrm{a} 1$ \\
1 & $1.204,25$ & $\mathrm{a} 2$ & 3 & 143,75 & $\mathrm{a} 1$ \\
3 & $1.206,00$ & $\mathrm{a} 2$ & 1 & 144,00 & $\mathrm{a} 1$ \\
2 & $1.218,00$ & $\mathrm{a} 2$ & 4 & 145,00 & $\mathrm{a} 1$ \\
4 & $1.219,75$ & $\mathrm{a} 2$ & 2 & 145,00 & $\mathrm{a} 1$ \\
\hline *: 1: ACS parcela circular; 2: ACS parcela em linha; 3: Krigagem parcela circular; 4: Krigagem parcela em linha; 5: Censo.
\end{tabular}

Tabela 7. Teste de média Scott-Knott para número de fustes e volume, na intensidade 1:7.

Table 7. Means test Scott-Knott for stem number and volume, in the intensity 1:7.

\begin{tabular}{lccccc}
\hline \multicolumn{4}{c}{ Número de fustes } & \multicolumn{3}{c}{ Volume } \\
\hline Tratamentos* & Médias & Resultado & Tratamentos* & Médias & Resultado \\
\hline 5 & $1.139,50$ & $\mathrm{a} 1$ & 5 & 136,50 & $\mathrm{a} 1$ \\
3 & $1.253,00$ & $\mathrm{a} 2$ & 3 & 150,00 & $\mathrm{a} 1$ \\
1 & $1.253,75$ & $\mathrm{a} 2$ & 1 & 150,25 & $\mathrm{a} 1$ \\
4 & $1.268,50$ & $\mathrm{a} 2$ & 4 & 151,25 & $\mathrm{a} 1$ \\
2 & $1.269,75$ & $\mathrm{a} 2$ & 2 & 151,25 & $\mathrm{a} 1$ \\
\hline *: 1: ACS parcela circular; 2: ACS parcela em linha; 3: Krigagem parcela circular; 4: Krigagem parcela em linha; 5: Censo.
\end{tabular}

Tabela 8. Teste de média Scott-Knott para número de fustes e volume, na intensidade 1:10.

Table 8. Means test Scott-Knott for stem number and volume, in the intensity 1:10.

\begin{tabular}{lccccc}
\hline \multicolumn{3}{c}{ Número de fustes } & \multicolumn{3}{c}{ Volume } \\
\hline Tratamentos* & Médias & Resultado & Tratamentos* & Médias & Resultado \\
\hline 5 & $1.139,50$ & a1 & 5 & 136,50 & a1 \\
4 & $1.261,50$ & a2 & 4 & 149,75 & a2 \\
2 & $1.264,75$ & a2 & 2 & 149,75 & a2 \\
3 & $1.282,00$ & a2 & 1 & 153,50 & a2 \\
1 & $1.283,25$ & a2 & 3 & 153,50 & a2 \\
\hline$*:$ 1: ACS parcela circular; 2: ACS parcela em linha; 3: Krigagem parcela circular; 4: Krigagem parcela em linha; 5: Censo.
\end{tabular}

Observando-se as médias dos volumes por tratamento, para as intensidades amostrais de 1:7 e 1:10, nota-se que as amplitudes entre o maior e o menor valor foi muito semelhante. Apesar disso, o teste conseguiu detectar diferença significativamente entre os tratamentos e somente na intensidade de 1:10 o volume obtido por meio do censo diferiu dos volumes obtidos por meio dos demais tratamentos.

Além dos resultados da análise de variância, optou-se no presente estudo por efetuar uma avaliação detalhada sobre a matriz de exatidão para número de fustes e volume, apresentadas nas tabelas 9 e 10. A exatidão foi calculada com base no valor observado do número de fustes e de volume. Para número de fustes, os tratamentos mais exatos foram os que se basearam em parcelas circulares, ou seja, $5,78 \%$ para amostragem casual simples (ACS) e $-5,83 \%$ para krigagem.

Tabela 9. Matriz de exatidão para número de fustes.

Table 9. Accuracy matrix for stems number.

\begin{tabular}{lccc}
\hline \multirow{2}{*}{ Método } & \multicolumn{3}{c}{ Intensidade amostral } \\
\cline { 2 - 4 } & $\mathbf{1 : 4}$ & $\mathbf{1 : 7}$ & $\mathbf{1 : 1 0}$ \\
\hline ACS Parcela Circular & $-5,74 \%$ & $-10,02 \%$ & $-12,66 \%$ \\
ACS Parcela em Linha & $-6,97 \%$ & $-11,50 \%$ & $-11,12 \%$ \\
Krigagem Parcela Circular & $-5,84 \%$ & $-9,96 \%$ & $-12,50 \%$ \\
Krigagem Parcela em Linha & $-7,06 \%$ & $-11,33 \%$ & $-10,78 \%$ \\
\hline
\end{tabular}


Tabela 10. Matriz de exatidão para volume.

Table 10. Accuracy matrix for volume.

\begin{tabular}{lccc}
\hline \multirow{2}{*}{ Método } & \multicolumn{3}{c}{ Intensidade amostral } \\
\cline { 2 - 4 } & $\mathbf{1 : 4}$ & $\mathbf{1 : 7}$ & $\mathbf{1 : 1 0}$ \\
\hline ACS Parcela Circular & $-5,39 \%$ & $-9,78 \%$ & $-12,18 \%$ \\
ACS Parcela em Linha & $-6,18 \%$ & $-10,56 \%$ & $-9,61 \%$ \\
Krigagem Parcela Circular & $-5,28 \%$ & $-9,85 \%$ & $-12,18 \%$ \\
Krigagem Parcela em Linha & $-6,33 \%$ & $-10,85 \%$ & $-9,61 \%$ \\
\hline
\end{tabular}

Para a intensidade de uma parcela a cada dez hectares, a mesma adotada no inventário florestal contínuo, os tratamentos que se basearam em parcelas em linha apresentaram maior exatidão $(-9,6 \%$ para a ACS e $-9,6 \%$ para a krigagem). Assim, tratando-se de baixa intensidade amostral, parcelas em linha propiciaram melhores estimativas de número de fustes e de volume. Esse mesmo comportamento foi verificado para volume. Isso ocorreu devido ao fato de que, proporcionalmente, as parcelas em linha amostraram uma área maior do que as parcelas circulares na mesma intensidade.

Para volume, na intensidade de uma parcela a cada 10 hectares, os valores obtidos pelo método da krigagem foram iguais aos valores obtidos pelo método da amostragem casual simples, para os dois tipos de parcelas. Isso ocorreu, nessa intensidade amostral, devido à falta da estrutura de continuidade espacial, para a variável volume nessa intensidade amostral. Desse modo, os dados devem ser considerados de forma independente.

\section{CONCLUSÕES}

Pela análise de variância, concluiu-se que, para número de fustes, os tratamentos ACS - parcela circular, ACS - parcela em linha, krigagem - parcela circular e krigagem - parcela em linha, apresentaram diferença significativa em relação ao censo, nas três intensidades amostrais. Já para volume, os tratamentos foram estatisticamente iguais ao censo nas maiores intensidades amostrais (1:4 e 1:7).

Quanto à matriz de exatidão, os métodos mais exatos para número de fustes e volume foram os que se basearam em parcelas circulares. Para a intensidade de uma parcela a cada dez hectares, os métodos que se basearam em parcelas em linha foram mais exatos. Assim, tratando-se de baixa intensidade amostral, parcelas em linha propiciaram melhores estimativas de número de fustes e de volume. Dessa forma, conforme os resultados apresentados neste trabalho, nos inventários contínuos com a intensidade de 1:10 hectares, deve-se utilizar parcelas em linhas para se obter melhor precisão das estimativas.

\section{REFERÊNCIAS}

COCHRAN, W. G. Sampling techniques. 3. ed. New York: Wiley, 1977. 555 p.

CESARO, A. de; ENGEL, O. A.; FINGER, C. A. G.; SCHNEIDER, P. R. Comparação dos métodos de amostragem de área fixa, relascopia e de seis árvores, quanto a eficiência, no inventário florestal de um povoamento de Pinus sp. Ciência Florestal, Santa Maria, v. 4, n. 1, p. 97-108, jun. 1994.

GOMES, F. P. Estatística experimental. Piracicaba: Escola Superior de Agricultura "Luiz de Queiroz" ESALQ, 1990. 468 p.

JOURNEL, A. G.; HUIJBREGTS, C. J. Mining geostatistics. London: Academic, 1978. 600 p.

MELLO, J. M. Geoestatística aplicada ao inventário florestal. 110 p. Tese (Doutorado em Recursos Florestais, Silvicultura e Manejo Florestal) - Escola Superior de Agricultura "Luiz de Queiroz", Universidade de São Paulo, 2004.

MELLO, J. M.; OLIVEIRA, M. S.; BATISTA, J. L. F.; RIBEIRO JR, P. J.; KANEGAE JR, H. Uso do estimador geoestatístico para predição volumétrica por talhão. Floresta, Curitiba, v. 36, n. 2, p. 251-260, mai./ago. 2006. 
MOSCOVICH, F. A.; BRENA, D. A.; LONGHI, S. J. Comparação de diferentes métodos de amostragem, de área fixa e variável, em uma floresta de Araucária angustifolia. Ciência Florestal, Santa Maria, v. 9, n. 1, p. 173-191, jun. 1999.

PÉLLICO NETTO, S.; BRENA, D. A. Inventário florestal. Curitiba: Universidade Federal do Paraná: Santa Maria: Universidade Federal de Santa Maria, 1997. 316 p.

RIBEIRO JUNIOR, P. J.; DIGGLE, P. J. geoR: A package for geostatistical analysis. R-NEWS, London, v. 1, n. 2, p. 15-18, June 2001.

ROBLES, C. Estadística. Santiago del Estero: Facultad de Ciências Forestales. Universidad Nacional de Santiago del Estero, 1978. 285 p.

SCOLFORO, J. R. S.; MELLO, J. M. Inventário florestal. Lavras: UFLA/FAEPE, 2006. 561 p.

SCOTT, S. J.; KNOTT, M. A cluster analysis method for grouping means in the analysis of variance. Biometrics, Washington, DC, v. 30, n. 3, p. 507-512, Sept. 1974.

SOARES, A. G. Geoestatística para as ciências da terra e do ambiente. Lisboa: IST, 2000. 186 p. 